\title{
Disposiciones para la catalogación de empresas de caballeros españoles entre los siglos XV-XVII a través de bases de datos
}

\author{
Andrea MACEIRAS LAFUENTE \\ Universidade da Coruña \\ andreamaceiras@hotmail.com
}

\section{RESUMEN}

Las empresas o divisas (asociación de palabra e imagen) fueron utilizadas por reyes y caballeros como forma de ostentación de altos ideales heroicos o amatorios entre los siglos XV y XVII. Para elaborarlas, requerían de la pericia de poetas y humanistas con buenos conocimientos de los clásicos, Retórica y dominio de la agudeza conceptual y verbal. Por su condición de arte efímero, hemos perdido gran parte de esas creaciones, a excepción de las que nos han quedado descritas en relaciones de torneos, de fiestas, de viajes, genealogías de caballeros, descripciones de cimeras de los blasones, etc. Presentaremos un proyecto de repertorio de estas composiciones a través del uso de bases de datos.

Palabras clave: Empresas, divisas, catálogo, bases de datos.

\begin{abstract}
Impresses or devices (association of word and image) were used by kings and knights as a way of flaunting heroic or amatory ideals between the XV and XVII centuries. To elaborate them, it was necessary the expertise of poets and humanists with a good knowledge about classics, Rhetoric and domain of verbal and conceptual acuity. Because of their ephemeral art condition, we have lost the most of those creations, with the exception of the impresses and devices that are described in relations about tournaments, celebrations, travels, knights genealogies, descriptions of coats of arms, etc. We are going to present a project of catalogue of those compositions through the use of databases.
\end{abstract}

Keywords: Impresses, devices, catalogue, database.

A lo largo de las últimas décadas han aumentado los que hasta hace no mucho eran escasos estudios centrados en la rama de la emblemática que se ocupa de modo particular de las insignias personales de reyes, reinas, caballeros y damas. Estas manifestaciones individuales, cuya función era la de singularizar a su portador, especialmente en el ámbito de la vida pública, se caracterizaban por presentar una 
naturaleza dupla, ya que estaban formadas por una imagen que se llamaba cuerpo (a la cual hoy solemos denominar pictura), acompañada de una o varias palabras, por lo general en latín, que recibían el nombre de mote, lema o alma (y que hoy denominamos inscriptio). Las empresas y motes constituyen un subgénero de la emblemática por diversas razones entre las que destaca su funcionalidad: mientras que los emblemas persiguen distintos fines entre los que habitualmente sobresale el didáctico o moralizante, las empresas y motes estaban destinados a la transmisión de altos ideales heroicos o amatorios y su efectividad comunicativa dependía de la pericia de su creador, que en la mayor parte de los casos no era el propietario, sino un humanista versado en retórica y agudeza verbal y conceptual. La diferencia entre empresas y divisas propiamente dichas y motes o letras de justadores radica esencialmente en su perdurabilidad: mientras que las primeras poseían un carácter más o menos estable y duraban habitualmente lo que la vida de su propietario, las segundas se prestaban a un uso ocasional en eventos festivos puntuales.

Debido en parte a estas diferencias intrínsecas, pero también a otros factores relacionados con la naturaleza y entorno en el que nacen y se desarrollan empresas y motes, tales como su ostentación en festejos cortesanos, su entidad esencialmente poética, su estrecha vinculación entre el mensaje y la identidad de sus creadores y propietarios o lo dilatado de su uso en el tiempo, los estudios referidos a este género de la emblemática parten de intereses diferentes y variados y obtienen resultados parciales en su mayoría. Los interesados en estas manifestaciones extremadamente ricas coinciden en reclamar más estudios desde un enfoque multidisciplinar que atienda a todos los procesos implicados en la intención, creación, difusión y uso de empresas o divisas, ya que estas se caracterizaban por aunar en sus manifestaciones no solo texto e imagen (o, si se prefiere, inscriptio y pictura) sino también ostentación y gala, agudeza e ingenio, concisión y profundidad, declaración de ideales y expresión de sentimientos $\mathrm{y}$, en definitiva, gran parte de la pluralidad que daba entidad al día a día de la vida cortesana de los siglos XV, XVI y XVII, en la que la importancia de las apariencias era definitiva.

Así, desde la perspectiva más general a la más concreta, son varios los estudiosos que, en los últimos tiempos, atienden a este género que supone una de las aplicaciones más reales y palpables de la emblemática. Ya sea partiendo de un enfoque social, como en el caso de Díez Garretas ${ }^{1}$, que se centra en la relevancia crucial de estas manifestaciones en eventos festivos, tales como torneos y justas; ya sea atendiendo a la creación y tradición poética de motes concretos, como el penacho de penas analizado por Francisco Rico ${ }^{2}$, parece evidente el interés suscitado por este tipo de creaciones difíciles de adscribir a un campo concreto, pero indefectiblemente ligadas al arte, cultura e ideología del momento, en tanto que de ellas nacen y se

${ }^{1}$ M. J. Díez Garretas (1999), pp. 163-174.

${ }^{2}$ F. Rico (1990), pp. 189-228. 
nutren. Su relevancia queda patente no solo en el plano de lo real, sino también en el de lo ficticio, puesto que la gran difusión de estas manifestaciones hace que sean imitadas en novelas y libros de caballerías, como las analizadas por Alberto Río Nogueras $^{3}$ en su artículo "Libros de caballerías y poesía de cancionero: invenciones y letras de justadores". Por otra parte, el proceso de influencia no solo fue en la dirección realidad ficción, sino que la ficción fue a su vez imitada por los caballeros auténticos para representaciones lúdicas cortesanas, produciéndose así una realimentación mutua.

Más próximos a la elaboración de estudios con carácter de repertorio cabe mencionar nombres como Ian Macpherson ${ }^{4}$, que analiza y edita los motes existentes en el Cancionero General de Hernando del Castillo, John Gornal, que hace lo propio con el Cancionero de la British Library o Patrizia Botta ${ }^{5}$, que viene a completar este panorama con su trabajo sobre los motes y la rúbrica de los mismos en el Cancionero de García de Resende. En consonancia con esta línea de investigación, se hallan los trabajos de Manuel Moreno del Pulgar, quien aborda el estudio de las empresas de Batallas y Quincuagenas ofreciendo un catálogo de las mismas, con la diferencia de que se centra en ellas como realidad histórica y no meramente poética.

Siguiendo la estela de los avances producidos en los últimos años, precisamente encaminados hacia esta apertura de enfoque en el estudio de la empresa, y gracias a nombres como el citado Manuel Moreno del Pulgar, pero también a trabajos de investigación como los de Sagrario López Poza ${ }^{6}$, o de catalogación como el de Alan Young, que ofrece un amplio conjunto de empresas inglesas ordenadas y estructuradas a modo de repertorio, he comenzado a realizar un trabajo que será mi tesis doctoral, cuya finalidad es la de realizar un catálogo en el que se incluyan las empresas o divisas y las invenciones y letras de reyes y de caballeros españoles entre los siglos XV y XVII.

Esta acotación temporal coincide con el inicio del género en España y sus primeras manifestaciones en los cancioneros, y con el declive del mismo, que tendrá lugar de forma definitiva durante siglo XVIII. Como en todos los géneros, la preceptiva se ocupó de él cuando llevaba largo tiempo en práctica y, como es natural, no siempre refleja la realidad, sino que establece consideraciones acerca de cómo debería ser la perfecta empresa.

Así, en 1551, Paolo Giovio establece unos mínimos deseables en su Diálogo de las empresas militares y amorosas (que no se imprimió hasta 1555) y la culminación de esta preceptiva se consigue con Emanuele Tesauro en su obra Il Cannochiale Aristotélico de 1654 y L'idea delle perfette imprese (1622). Común a estas pre-

\footnotetext{
${ }^{3}$ A. Río Nogueras (1994), pp. 303-318.

${ }^{4}$ I. McPherson (2004).

${ }^{5}$ P. Botta (2005), pp. 173-192.

${ }^{6}$ S. López Poza (2008), pp. 17-63.
} 
ceptivas es la atención a diversas características relativas tanto a la inscriptio como a la pictura: desde su apariencia hermosa hasta la profundidad de su significado o la preferencia por motivos vegetales y animales en lugar de humanos. En lo que se refiere a España, son muy ilustrativas las consideraciones iniciales de Fernández de Oviedo en su Libro del Blasón. También es destacable la nutrida información que se desprende de su obra Batallas y Quinquagenas, relativa a costumbres, hábitos y uso de estas manifestaciones.

Pero sobre todas estas cualidades ha sido ensalzada como fundamental la de la brevedad, que sin embargo no actúa en demérito de su capacidad expresiva y comunicativa, sino más bien al contrario, ya que el sucinto enunciado del mote de las empresas, acompañado generalmente por la imagen simbólica, está especialmente diseñado para albergar dentro de sí la mayor cantidad de significado posible y, como ya hemos visto, establece relación con otras muchas realidades de diversa índole. En este sentido podría ser comparado con el agujero de una cerradura que, a pesar de su tamaño, permite entrever, al otro lado, una realidad diversa y compleja que esconde más significados de los que muestra en apariencia. Por otra parte, no se debe perder de vista el hecho de que su entidad era efectiva, es decir, que la empresa cumplía una función pública, con un carácter que podía ser más o menos lúdico, pero que, en todo caso, trascendía los límites de cualquier ficción literaria para incardinarse en la realidad histórica. El fenómeno de la empresa, con todo lo que suponía, podría, quizá, equipararse al hecho de que hoy en día muchos usuarios de redes sociales y de internet en general emplean frases e imágenes definitorias de sus gustos e intereses para dar a conocer su personalidad franqueando la barrera de la pantalla. Estas frases, que no suelen ser de su autoría, tienen entidad literaria en muchos casos, pero una vez incluidas en el juego de las apariencias virtuales cumplen una función distinta de la original y muy semejante a la de los motes que los caballeros lucían en sus atuendos durante los torneos, las cuales permitían adivinar la identidad del justador a pesar de que su rostro quedase oculto por el yelmo.

Partiendo, pues, de este enfoque plural que entiende la empresa como elemento fundamental de la vida pública y como hecho real estrechamente conectado con su entorno y con su época, capaz de generar alrededor de sí misma una cultura propia, pretendemos recoger en el catálogo de motes y empresas el mayor número posible de estas manifestaciones atendiendo a sus diversas facetas, de modo que no solo se contemplen como hechos aislados, sino que se obtenga una visión de conjunto, histórica y artística, sin olvidar que la principal particularidad de una empresa o mote es su naturaleza dupla, visual y escrita. Somos conscientes de que en un número importante de casos solo se conserva la inscriptio, en tanto que la vida de la figura suele ser más efímera. Las imágenes se pierden con mayor facilidad debido, entre otras circunstancias, a los variados soportes sobre los que podían lucirse, ya que además de plasmarse sobre el papel, podían ser ostentadas en adargas, cimeras, en 
la propia vestimenta del caballero o incluso en fachadas y entradas de edificios ${ }^{7}$. Sin embargo y, a pesar de estas inevitables carencias, el estudio de las empresas y motes no debe dejar de lado la parte pictórica, puesto, que salvo contadas ocasiones, la imagen está siempre presente en el momento de concepción de este tipo de creaciones.

Con la finalidad de aprovechar al máximo los resultados obtenidos, el objetivo último de este trabajo es el de la creación de una base de datos accesible a través de Internet que contenga la información recogida en el catálogo. Las múltiples ventajas que nos ofrecen los recursos web actuales y la cada vez más frecuente digitalización de textos por parte de bibliotecas e instituciones, comienzan a marcar indefectiblemente el discurrir de la investigación contemporánea. Materiales que antes eran difícilmente accesibles y, por esta causa, desconocidos en muchos casos, se ponen ahora al servicio del público a través de bibliotecas virtuales, páginas especializadas e incluso páginas de particulares, permitiendo obtener mayores resultados con menor esfuerzo. En este sentido, el uso de bases de datos constituye una de las herramientas de trabajo más rentables a todos los niveles, pues permite gestionar la información de forma óptima, aportando una inmediatez y una eficacia difíciles de conseguir sobre el papel. Aplicaciones estandarizadas de búsqueda y recuperación de datos agilizan la localización de la información al tiempo que el soporte digital permite llegar al mayor número de usuarios.

Así pues, con el empleo de estos recursos, toda la información contenida en el catálogo que estoy elaborando estará accesible de un modo ágil, dinámico y flexible, puesto que se adaptará a las necesidades de cada usuario, que podrá formular preguntas de tipo directo a la base de datos a través de las diferentes opciones de búsqueda.

En realidad, la metodología empleada para elaborar el catálogo, ya desde su fase más inicial, pasa también por el uso de una base de datos de estas características que permite volcar la información obtenida y cuyos registros ejemplificarían lo que podría ser una aproximación al resultado final del conjunto del trabajo. Atendiendo a la naturaleza de motes y empresas y, teniendo en cuenta que incluso dentro de una misma empresa pueden existir variaciones mínimas en el lema o la pictura, cada registro se corresponde con una empresa o mote en concreto. La información relativa a los mismos se distribuye en una serie de campos que explicaré a través de algunos ejemplos y que pretenden organizar la información de modo práctico.

En cuanto al proceso de elaboración, se basa, en primera instancia, en el rastreo de fuentes primarias en las que se incluyen las obras fundamentales que permitirán dotar de contenidos a la base de datos a medida que se vayan incorporando nuevas empresas. Estas fuentes serían, entre otras, libros de emblemas, genealogías, libros de heráldica o relaciones de sucesos, atendiendo especialmente a los grandes auto-

${ }^{7}$ S. López Poza, 2010, pp. 413-462. 
res del momento, desde Gonzalo Fernández de Oviedo hasta Giovio, Girolamo Ruscelli, Camilo Camilli, Ludovico Dolce, Bargagli o Capaccio, puesto que todos ellos recogen en sus obras empresas de caballeros españoles.

Inicialmente, los límites de este rastreo se centrarán, en lo relativo a la naturaleza del texto, a textos de carácter impreso, y, por lo que respecta a las fechas, al período comprendido entre los siglos XV y XVII, debido a las causas ya mencionadas. Además se seleccionarán aquellos motes y empresas que tengan entidad real y efectiva, desechando los pertenecientes a obras de ficción. Sin embargo, y puesto que se trata de un proyecto que aún está en una fase de asentamiento y desarrollo, es lógico suponer que vayan a existir modificaciones que, si bien no afectarán a la esencia de esta propuesta, podrán alterar estas acotaciones iniciales y abrir o cerrar las restricciones en cuanto a las fuentes, fechas y naturaleza de los motes y empresas dependiendo de los resultados obtenidos, con el fin de enriquecer el trabajo.

Además de la localización y lectura de las fuentes y del vaciado de los datos en la base, también consideramos relevante dar cuenta de otros aspectos fundamentales a la hora del estudio del género, de modo que pretendemos investigar no sólo la información concerniente a los textos e imágenes, sino también a la vida de los reyes y caballeros que lucen estas empresas y motes y a los acontecimientos en los que fueron ostentados, puesto que la relación que existe entre la empresa, su portador y su contexto es demasiado estrecha como para dejarla de lado o atenderla solamente en un sentido marginal. Tal y como hemos visto, una de las principales particularidades de este género de la emblemática es su capacidad de establecer relaciones con su entorno y, en este sentido, muchas empresas solo pueden cobrar significado pleno a la luz de las circunstancias vitales de sus propietarios, puesto que aluden a hechos biográficos significativos y a ideales personales. Otro tanto sucede con los motes que, además, varían según las circunstancias del torneo y en muchas ocasiones hacen referencia al motivo por el cual se organiza el festejo, como pueden ser una boda real o la visita de miembros de la realeza.

Para la adecuada organización de todas estas informaciones que rodean y otorgan su esencia a las empresas, hemos creado una serie de campos en cada uno de los registros de la base de datos destinados a recoger aquellos aspectos más representativos. Estos campos son: el mote, su traducción, su fuente primaria, el propietario y sus datos biográficos (vida) y personales $(\mathrm{H} / \mathrm{M})$, la descripción de la imagen, el lugar donde se ostentó la empresa, su carácter real o ficticio, la existencia de posibles fuentes secundarias que aludan a la empresa, el hecho de que esta sea personal u ocasional, el acontecimiento en el que se ostenta, el autor, y, por último, si va acompañada de ilustración, y, en caso afirmativo, si la conservamos o si conservamos alguna imagen similar.

A continuación presento algunos ejemplos. 


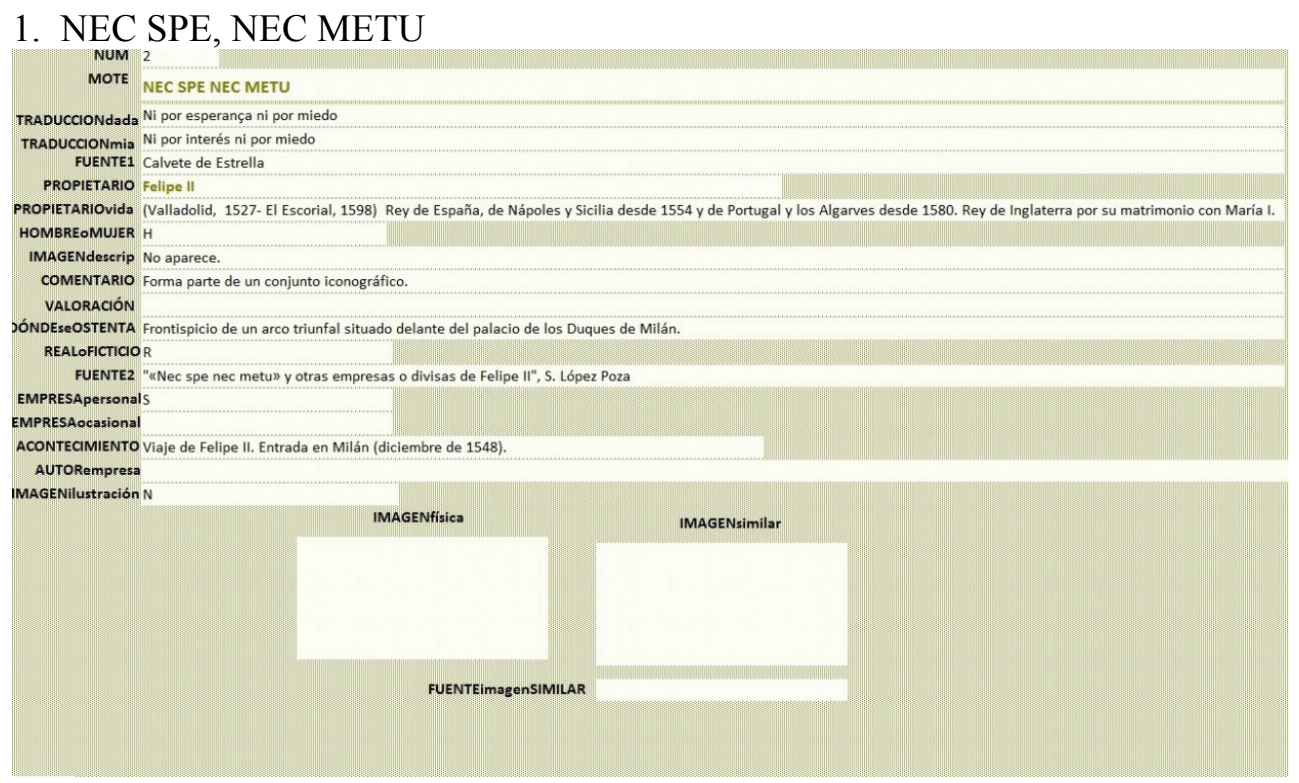

Esta empresa está tomada de la obra de Juan Calvete de Estrella titulada El felicissimo viaje del muy alto y muy poderoso Príncipe don Phelippe, hijo del emperador don Carlos Quinto Máximo, desde España a sus tierras de la baxa Alemana: con la descripción de todos los Estados de Brabante y Flandes ${ }^{8}$, donde se relata la visita del príncipe Felipe II a los estados europeos de su padre, el emperador Carlos. En su crónica, Calvete de Estrella presta especial atención a los festejos con los que el príncipe era agasajado a su paso por las diferentes villas y ciudades, los cuales incluían arcos de triunfo y variados programas iconográficos decorados con las empresas del príncipe y su familia. La empresa que nos ocupa, NEC SPE NEC METU es, presumiblemente, la primera de las empresas que Felipe II usó a lo largo de su vida. Se trata, por tanto, de una empresa de carácter personal, que presenta la particularidad de no poseer pictura, por lo que no aparece la descripción de la misma. Si bien Calvete de Estrella ofrece la traducción "ni por esperanza ni por miedo", el significado de la palabra 'esperanza' en la época y contexto en que fue ostentada, se asemeja más al de 'interés' o 'expectativa', de ahí que podamos traducirlo como "ni por interés ni por miedo"'.

En este caso, el evento en el que aparece es la entrada del príncipe en Milán en diciembre de 1548 y el lugar donde se ostenta un arco del triunfo preparado para la ocasión. Completa el registro un artículo relativo a la empresa del príncipe que se consigna como bibliografía secundaria.

${ }^{8}$ Primera edición de 1552, Amberes.

${ }^{9}$ S. López Poza, 2011, pp. 435-456 


\section{LOS LLENOS DE DOLOR Y LOS VACÍOS DE ESPERANZA.}

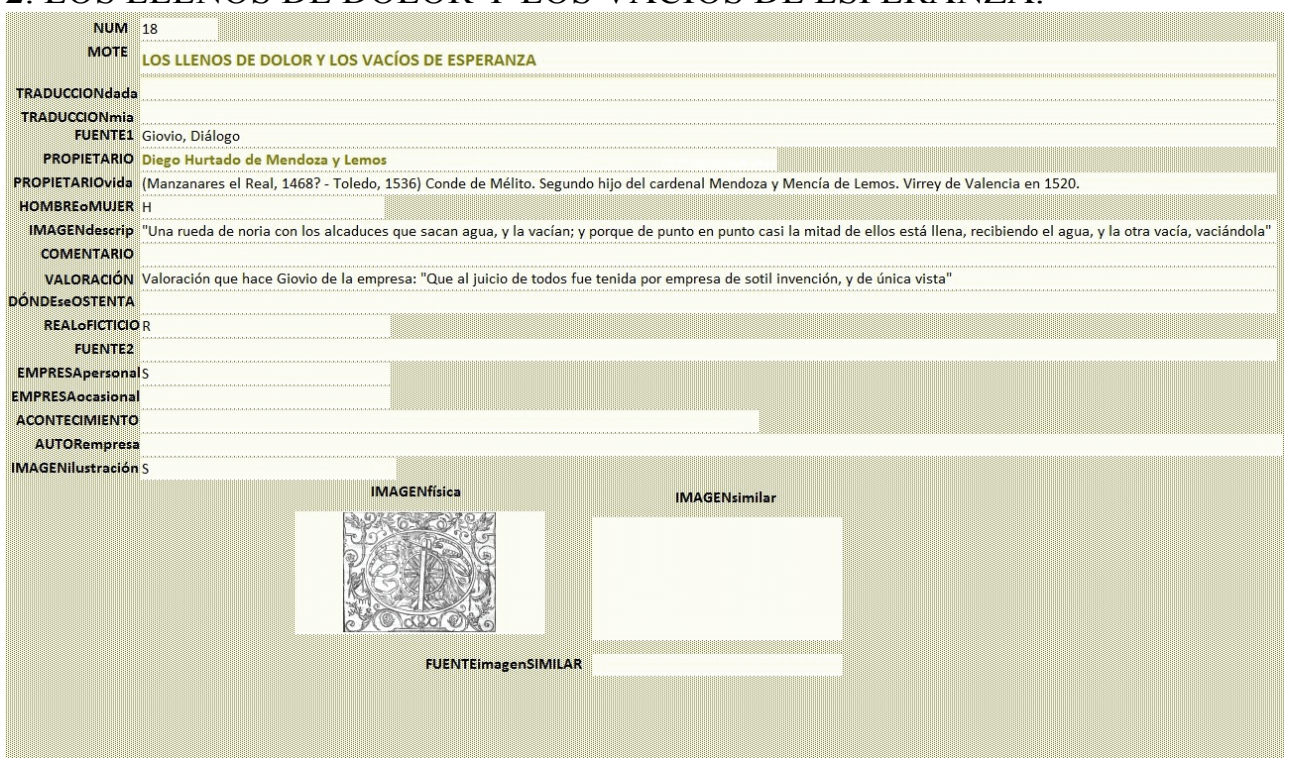

Esta empresa figura en el Diálogo de las empresas militares y amorosas de Paolo Giovio $^{10}$, obra que recoge numerosas empresas de caballeros principalmente españoles e italianos, y pertenece a Diego Hurtado de Mendoza y Lemos, conde de Mélito. Se trata de una empresa personal que este caballero debió de lucir en diversas ocasiones a lo largo de su vida, pero en la obra de Giovio no se da cuenta de las mismas ni del lugar donde fue ostentada. Esta empresa de índole marcadamente amorosa es, sin embargo, valorada por el preceptista como "de sotil invención y única vista", por lo que en su época debió de gozar de gran consideración social. En la pictura aparece una noria en la que algunos de los cangilones van llenos y otros vacíos, de modo que el pleno significado de la empresa se obtiene a la luz de la inscriptio: los llenos de dolor y los vacíos de esperanza. En este caso, conservamos esa imagen que representa una noria rodeada de abundante ornamentación con el mote del emblema escrito en una filacteria.

${ }^{10}$ Edición de 1561, Lyon, Guillermo Roville, traducido por Alonso de Ulloa. 


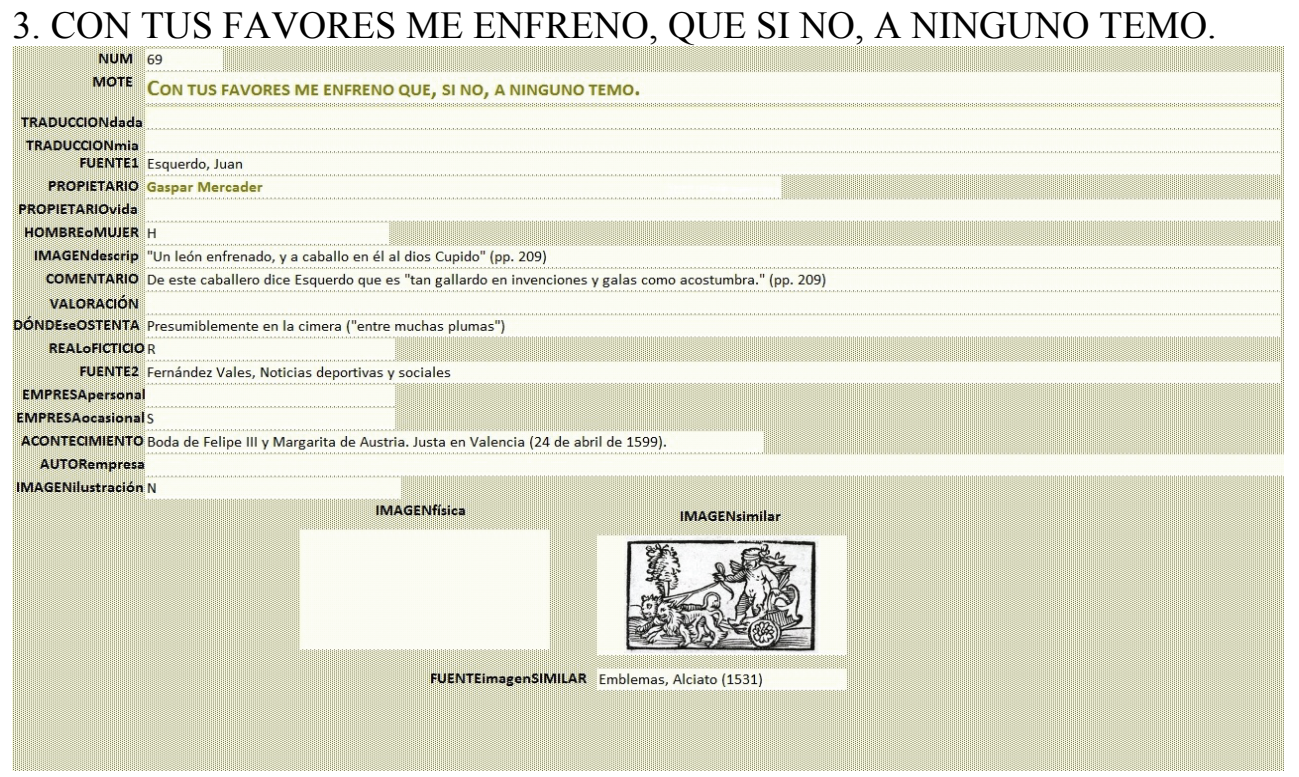

Esta empresa está tomada del Tratado Copioso y verdadero de la determinación del gran Monarca Felipe II para el casamiento del III con la Serenísima Margarita de Austria, y entradas de Sus Majestades y Grandes por su orden en esta ciudad de Valencia con las libreas, galas y fiestas que se hicieron ${ }^{11}$. El autor de esta relación, Juan Esquerdo, describe con gran detalle cómo fueron los festejos celebrados en honor de las bodas del Príncipe Felipe III con la princesa Margarita de Austria. Precisamente, una de las celebraciones con las que se honró a la princesa en Valencia, fue el torneo que tuvo lugar el 24 de abril de 1599, al que acudió el caballero propietario de esta empresa: Gaspar de Mercader. Se trata, por tanto, de una empresa de uso ocasional que el justador lució, presumiblemente, en su cimera, completando su ornamentación con algunas plumas.

La empresa de Gaspar de Mercader aúna el ideal heroico con la declaración del sentimiento amoroso. Así, en la pictura de la misma figuran un león, animal representativo de valor y fortaleza, que es sometido por el dios del amor, Cupido. El mote que complementa la imagen, explicita su significado: solo el amor de la dama puede templar el furioso ímpetu del caballero. A pesar de que en este caso no conservamos la pictura de la empresa, sino tan solo su descripción, se trata de un motivo recurrente, por lo que es posible asociarle una imagen similar, que en este caso he tomado del emblema de Alciato "Potentissimus afectus Amor" el cual figura en su obra Emblematum liber. Complementan el registro la valoración de Esquerdo acerca de esta empresa y un artículo relativo al tema.

${ }^{11}$ Edición de 1559, Valencia. 
Todas estas consideraciones conforman el proyecto de una investigación que se encuentra en su fase inicial, de modo que solo he podido trabajar en su metodología. Espero que pueda estar terminada en dos o tres años y que, de ser posible la instalación de la base en Internet, sirva de plataforma para ampliar el catálogo con aportaciones futuras de otros posibles colaboradores.

\section{Obras citadas}

BOTTA, Patrizia: "La rubricación cancioneril de las letras de justadores", en Dejar hablar a los textos, homenaje a Francisco Villanueva, ed. Pedro M. Piñero Ramírez, Sevilla, 2005, pp. 173-192.

BREGOLI RUSSO, Mauda: L'impresa come ritratto del Rinascimento, Napoli, Loffredo, 1990.

CARCELlER CERVIÑo, María del Pilar: "La nobleza caballeresca castellana en el siglo XV: realidad y representación de un grupo social", Medievalismo: Boletín de la Sociedad Española de Estudios Medievales, 10 (2000), pp. 99-128.

CARrillo CASTILlo, Jesús: "Cultura cortesana e imperio: El Libro del Blasón, de Gonzalo Fernández de Oviedo", Locvs Amoenvs, 4 (1998-1999), pp. 137-154.

DíEz GARRETAS, María Jesús: "Fiestas y juegos cortesanos en el reinado de los Reyes Católicos. Divisas, motes y momos", Revista de Historia Jerónimo Zurita, 74 (1999), pp. 163-174.

DOMÍNGUEZ CASAS, Rafael: "Las divisas reales: estética y propaganda", en Isabel la Católica y su época: actas del Congreso Internacional, ValladolidBarcelona-Granada, 15 a 20 de noviembre de 2004, I, Valladolid, Instituto Universitario de Historia Simancas, 2007, pp.335-360.

FERNÁNDEZ DE OvIEDO, Gonzalo: Batallas y Quincuagenas, ed. Juan Pérez de Tudela y Bueso", Madrid, Real Academia de la Historia, 1983.

FERnÁNDEZ DE OVIEDO, Gonzalo: Batallas y Quincuagenas, Salamanca, Diputación, 1989.

GONZÁLEZ CUENCA, Joaquín: "Espectáculos nobiliarios de riesgo: el torneo y sus variantes", en Historia de los espectáculos en España, Madrid, Castalia, 1999.

GORNALL, John: The invenciones of the British Library Cancionero, London, Queen Mary, University of London, 2003.

LÓPEZ POZA, Sagrario: "Linajes de aguda invención figurada: las empresas", en Actas del V Congreso Internacional de la Sociedad Española de Emblemática Paisajes Emblemáticos: la construcción de la imagen simbólica en Europa y América, Cáceres, Junta de Extremadura, 2008, pp. 17-63.

LÓPEZ POZA, Sagrario: "Emblemática aplicada y artificios de la cultura visual en los juegos caballerescos del Siglo de Oro", en Cultura oral, visual y escrita en la España de los Siglos de Oro, dir. J. Ma. Díez Borque, eds. I. Osuna y E. Llergo, Madrid, Visor, 2010, pp. 413-462. 
LÓPEZ POZA, Sagrario: «"Nec spenec metu” y otras empresas o divisas de Felipe II», en Emblemática Trascendente, Rafael Zafra y Javier Azanza (eds.), Pamplona, Sociedad Española de Emblemática-Universidad de Navarra, 2011, pp. 435-456.

LÓPEZ POZA, Sagrario: "Empresas, emblemas, jeroglíficos: agudezas simbólicas y comunicación conceptual", en La aparición del periodismo en Europa. Comunicación y propaganda en el Barroco, Roger Chartier y Carmen Espejo (eds.), Madrid, Marcial Pons Historia, 2012, pp. 37-85.

LÓPEZ POZA, Sagrario: "Empresas o divisas de Isabel de Castilla y Fernando de Aragón (los Reyes Católicos)" en Janus. Estudios sobre el Siglo de Oro. 1 (2012).

MCPHERSON, Ian: Motes y glosas in the "Cancionero General", London, University, Department of Hispanic Studies, Queen Mary, 2004.

RICO, Francisco: "Un penacho de penas. De algunas invenciones y letras de justadores", en Texto y contexto. Estudio sobre la poesía española del XV, Barcelona, Crítica, 1990, 189-228.

Río NoGUERAS, Alberto: "Libros de caballerías y poesía de cancionero: invenciones y letras de justadores", en Actas del III Congreso de la Asociación Hispánica de Literatura Medieval, Salamanca 3 al 6 de octubre de 1989, Salamanca, Biblioteca Española del Siglo XV, 1994, pp. 303-318.

SEBASTIÁN, Santiago: Emblemática e historia del arte, Madrid, Cátedra, 1995. YOUNG, Alan: The English tournament imprese, New York, AMS Press, 1988. 